\title{
Elliptical Leaf Spring Shock and Vibration Mounts with Enhanced Damping and Energy Dissipation Capabilities Using Lead Spring
}

\author{
Moussa Leblouba, ${ }^{1}$ Salah Altoubat, ${ }^{1}$ \\ Muhammad Ekhlasur Rahman, ${ }^{2}$ and Balaji Palani Selvaraj ${ }^{2}$ \\ ${ }^{1}$ Department of Civil \& Environmental Engineering, College of Engineering, University of Sharjah, P.O. Box 27272, Sharjah, UAE \\ ${ }^{2}$ Department of Civil \& Construction Engineering, Faculty of Engineering and Science, Curtin University Sarawak, \\ Miri, Sarawak, Malaysia \\ Correspondence should be addressed to Moussa Leblouba; mleblouba@sharjah.ac.ae
}

Received 26 April 2015; Revised 29 May 2015; Accepted 2 June 2015

Academic Editor: Giuseppe C. Marano

Copyright ( $) 2015$ Moussa Leblouba et al. This is an open access article distributed under the Creative Commons Attribution License, which permits unrestricted use, distribution, and reproduction in any medium, provided the original work is properly cited.

\begin{abstract}
We present an enhancement to the existing elliptical leaf spring (ELS) for improved damping and energy dissipation capabilities. The ELS consists of a high tensile stainless steel elliptical leaf spring with polymer or rubber compound. This device is conceived as a shock and vibration isolator for equipment and lightweight structures. The enhancement to the ELS consists of a lead spring plugged vertically between the leaves (referred to as lead-rubber elliptical leaf spring (LRELS)). The lead is shown to produce hysteretic damping under plastic deformations. The LRELS isolator is shown to exhibit nonlinear hysteretic behavior. In both horizontal directions, the LRELS showed symmetrical rate independent behavior but undergoes stiffening behavior under large displacements. However, in the vertical direction, the LRELS behavior is asymmetric, exhibiting softening behavior in compression and stiffening behavior in tension. Mathematical models based on the Bouc-Wen model, describing the hysteretic behavior of the proposed isolator, are developed and numerically calibrated using a series of finite element analyses. The LRELS is found to be effective in the in-plane and vertical directions. The improved damping and energy dissipation of the LRELS is provided from the hysteretic damping of the lead spring.
\end{abstract}

\section{Introduction}

Shock and vibration isolation of sensitive equipment and machinery has become an integrated part of every engineering design. Vibrations may be from a natural source such as earthquakes or from artificial sources such as those originating from operating machines. Such vibrations may result in equipment failure, structural damage, or even human injuries, depending on the severity of the disturbing vibrations and the sensitivity of the equipment/facility. The widely used conventional systems for vibration isolation are passive types. The passive systems consist mainly of mechanical assemblies which are made up of different materials and designed to improve damping, stiffness, and strength of structures [1]. Since the passive energy dissipation devices are not an integral part of the main structure, they can easily be replaced without compromising the structural integrity [2]. Generally, passive isolators are placed at the base of the equipment, which is referred to as base isolation. The reduction of vibrations transmitted to the equipment is achieved with base isolation through an isolation system having a required energy absorption capability and with sufficient flexibility. This arrangement provides the equipment with a fundamental frequency that is much lower than both its fixed base frequency and the predominant frequency of the vibration signal [3-5].

Several isolation systems have been investigated $[3,6,7]$ and shown to enhance the seismic performance of individual equipment. The wire rope isolator [3, 8-10], spring-viscous damper systems [7], and Ball-N-Cone base isolation [11] are 
some of the systems developed mainly to isolate equipment. However, with lightweight equipment, it is difficult to achieve good shock and vibration isolation with traditional devices. To overcome this issue, the floor isolation technique has been introduced [12-14]. In this technique, a group of equipment items is mounted on a floor, which in turn is mounted on an isolation system. Analytical studies and shake table tests [1517] showed the effectiveness of the floor isolation technique in the seismic protection of equipment. However, in cases where the disturbance is due to the operation of machinery situated on the same floor as that of critical equipment, the isolation of individual equipment is required rather than the whole floor isolation. For instance, the elliptical leaf spring (ELS), a type of passive isolators, has found many applications in the isolation of individual equipment.

The ELS is a mechanical device designed to absorb the shock and vibration energy by undergoing deformation and then to release it. Hence, the strain energy stored in the material and the shape becomes a major factor in designing the springs. The experimental tests of the elliptical leaf spring confirm its ability in providing good isolation [18-20]. The company Advanced Antivibration Components, Inc. [21], develops a series of shock and vibration mounts including the elliptical leaf spring antivibration mounts. Their basic design employs two or more high ranges of tensile stainless steel U-formed leaves, situated at each end, forming an elliptical shape when joined together in the center portion with face plates. The spaces between the U-formed leaves are filled with a specially developed polymer (X-mounts) or stainless steel mesh (XM-mounts).

The ELS mounting was specifically designed for shipboard applications and is particularly suitable to protect marine equipment from shock due to underwater explosions. Further, ELS application has been extended to isolate heavy machinery, air compressors, engine suspensions, and sensitive equipment. The ELS operates effectively at low frequency and it is known for its ability to attenuate large shock inputs [21]. To attenuate high frequencies and provide sound isolation, the ELS is fitted with a viscoelastic rubber block (Ymounts) known as the accelerator unit [22]. The conventional ELS behaves elastically in both horizontal directions and nonlinearly elastically in the vertical direction which provides the flexibility to the system. However, the main disadvantage of the ELS is that it has high transmissibility at the resonant frequency due to limited damping from the polymer.

This paper presents a new design which has improved damping and energy dissipation over the original ELS design, referred to here as lead-rubber elliptical leaf sparing (LRELS), by incorporating a lead spring. The ELS described above can be readily converted into an LRELS by placing a lead spring down its center. The damping property of the ELS can be improved by plugging the lead spring with an appropriate size as in the lead-rubber bearings [23]. The lead material is chosen because it yields at relatively low stress (around $10 \mathrm{MPa}$ in some applications) and behaves almost as an elastic perfectly plastic solid [24]. In this paper, we investigate the cyclic behavior of the proposed passive isolator in all three directions using three-dimensional (3D) finite element analysis (FEA). Further, mathematical models describing the hysteresis behavior of the LRELS are developed based on the Bouc-Wen model of hysteresis $[25,26]$ and calibrated with numerical data.

\section{Description of the LRELS}

The LRELS vibration isolator is made of "U" shaped leaves connected together at their open ends to face plates and space plates to form an elliptical shaped assembly as shown in Figure 1. The leaves are made of high tensile stainless steel, while the compound between the inner and outer plates is made of rubber. A lead spring is plugged vertically between the top and bottom face plates. The lead material enhances the energy dissipation capability of the isolator. The spring shape of the lead insert is intended to provide the damping and energy dissipation capability in all directions, including the two horizontal directions (in-plane and out-of-plane). Hence, a number of isolators can be placed in different orientations and arrangements to achieve an optimum level of equipment vibration control.

The available standard sizes of the ELS are designed for nominal loads ranging from 10 to $450 \mathrm{~kg}$ under a wide range of temperatures. At low temperatures, the ELS is durable even under repeated shocks. The conventional ELS mounts operate at relatively low frequency and are capable of attenuating large shock inputs. However, the ELS has a high transmissibility at resonance. For temperatures ranging from $0^{\circ} \mathrm{C}$ to $40^{\circ} \mathrm{C}$ the natural frequency of the ELS mounts is almost constant. Their natural frequencies increase when the temperature decreases. ELS manufacturers use a special polymer as a damping compound. This polymer, which has a very low static stiffness, is used to achieve high damping efficiency. Although the ELS is normally used in tension and compression, the LRELS can be used for shock and vibration control in all directions. To obtain high load bearing capacity, several LRELS units can be combined together on one raft and placed at the base of a building floor. In this way, several similar equipment units can be isolated using the isolated raised floor technique.

\section{Finite Element Analysis}

The damping behavior and energy dissipation capabilities of the LRELS are investigated by performing a series of cyclic loading numerical analyses. The finite element models of the LRELS devices were developed and analyzed using ANSYS V14 software package [27]. ANSYS has been used in previous studies for understanding the behavior of similar devices [28] and different processes [29]. In building the 3D model of the device, the hexahedral element (ANSYS solid95, 20 nodes, structural solid) is used to model the "U" shaped leaves and the compound while the tetrahedral element (ANSYS solid92, 10 nodes, tetrahedral structural solid) is used to fill the remaining parts of the device. To maintain tetrahedra to hexahedra conformability, the interface between the two element types is transitioned using pyramid shaped elements [30].

The leaves, top, and bottom face plates were assigned AISI stainless steel type 302 material with an elastoplastic bilinear law. The 302 type of steel maintains higher ductility level while 


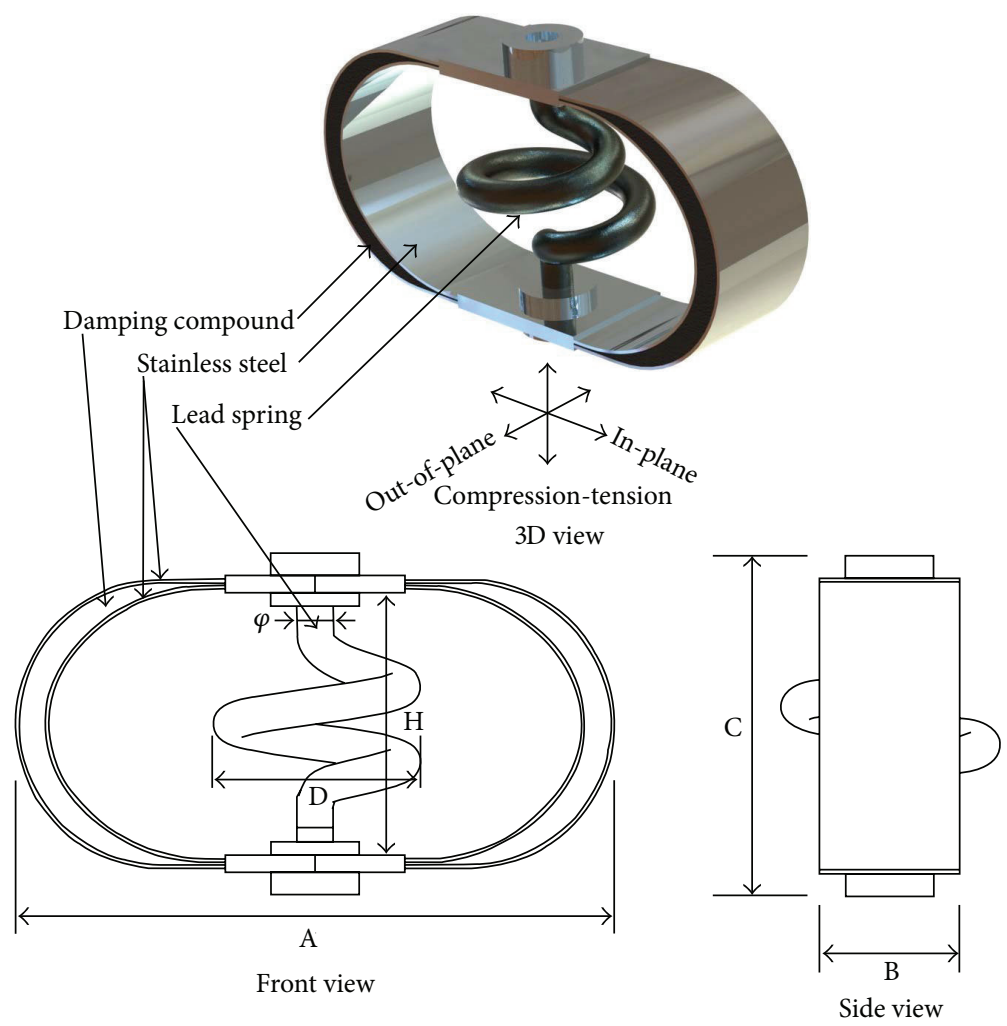

FIGURE 1: LRELS dimensions and loading directions.

meeting yield and tensile requirements. The ELS is made from stainless steel with Young's modulus $\left(E_{s}\right)$ of $200 \mathrm{GPa}$, Poisson's ratio of 0.25 , and a Von Mises yield criterion with yield strength of $250 \mathrm{MPa}$ and a tangent modulus of $0.05 E_{s}$ (Figure 2(a)). The lead material selected for the vertical spring is assumed to have Young's modulus of $16 \mathrm{GPa}$, Poisson's ratio of 0.44 , an elastic perfectly plastic constitutive law, and Von Mises yield criterion with yield strength of $30 \mathrm{MPa}$ (Figure 2(b)).

In this study, the compound between the inner and outer steel leaves is chosen to be filled by neoprene rubber. Although other damping materials could be assumed, the choice of the neoprene is primarily due to the availability of its mechanical properties as experimental data in ANSYS material database. Rubber is known for its capacity to recover from large deformations quickly, and it is characterized by a low elastic modulus and high bulk modulus. The neoprene rubber is an incompressible and hyperelastic material. The hyperelastic material law is defined by the strain energy function $W$, which can be expressed in terms of the strain invariants $I_{1}, I_{2}$, and $I_{3}$ or principal stretch rations $\lambda_{1}$, $\lambda_{2}$, and $\lambda_{3}$, depending on the hyperelastic material model [31]. Several material models are available to describe the hyperelastic stress-strain behavior of rubberlike materials. The polynomial form of the strain energy potential is the most general model; it is given by [32]

$$
W=\sum_{i, j=0}^{n} C_{i j}\left(\bar{I}_{1}-3\right)^{i}\left(\bar{I}_{2}-3\right)^{j}+\sum_{k=1}^{m} D_{k}(J-1)^{2 k},
$$

where

$$
\begin{aligned}
& \bar{I}_{1}=J^{-2 / 3} I_{1} ; \quad J=\lambda_{1} \lambda_{2} \lambda_{3}, \\
& \bar{I}_{2}=J^{-4 / 3} I_{2} .
\end{aligned}
$$

When $C_{01}=C_{11}=0$, the polynomial model reduces to the Neo-Hookean model. For consistency with linear elasticity, the Neo-Hookean model can be written as

$$
W=\frac{\mu}{2}\left(\bar{I}_{1}-3\right)+\frac{\kappa}{2}(J-1)^{2},
$$

where $\mu$ is the shear modulus and $\kappa$ is the bulk modulus. The Neo-Hookean model was used in this study to fit the curves obtained from the neoprene rubber experimental data (Figure 2(c)).

The LRELS isolators respond differently depending on their geometry and loading conditions. To determine their behavior in the horizontal (in-plane and out-of-plane) and vertical directions, a series of numerical finite element analyses (FEA) was performed on a number of isolators (Table 1) by imposing cyclic sinusoidal loads in a displacement controlled manner. Figure 3 shows the deformed shapes of the LRELS subjected to in-plane, out-of-plane, and vertical compression-tension displacements.

The behavior of the lead-rubber elliptical leaf spring (LRELS) isolator in each direction is studied through a series of three-dimensional (3D) finite element analyses (FEA) using ANSYS. The choice of the 3D modeling approach is dictated by the existence of the lead plug, which has a 


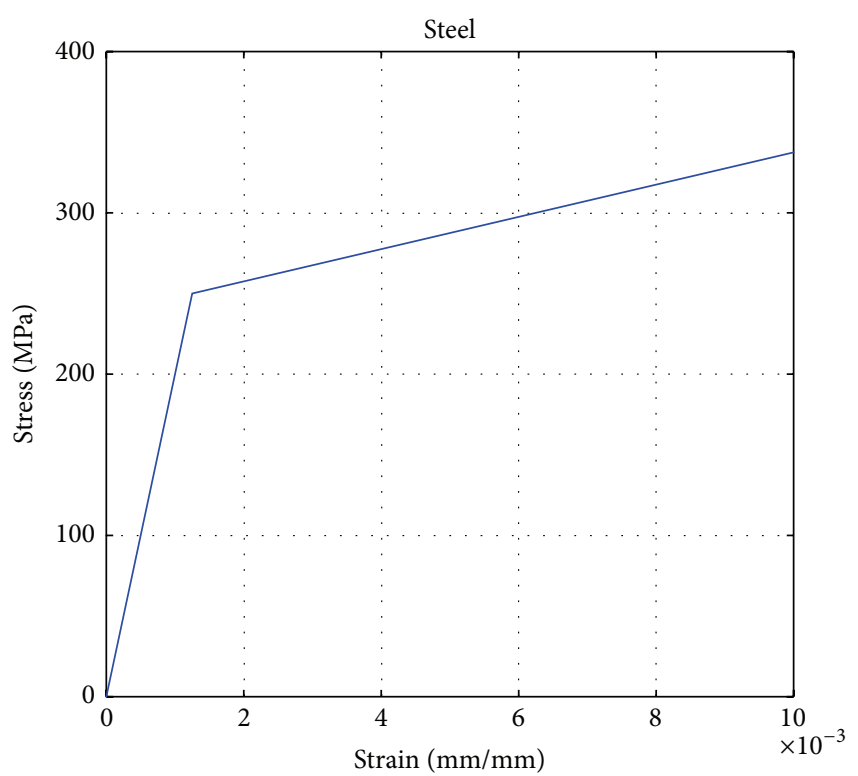

(a)

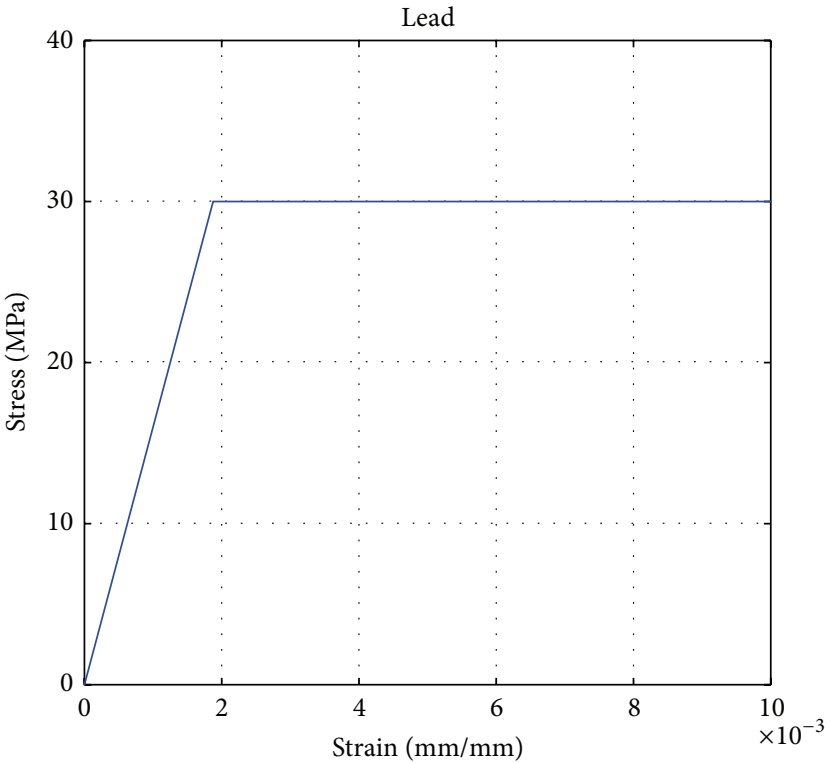

(b)

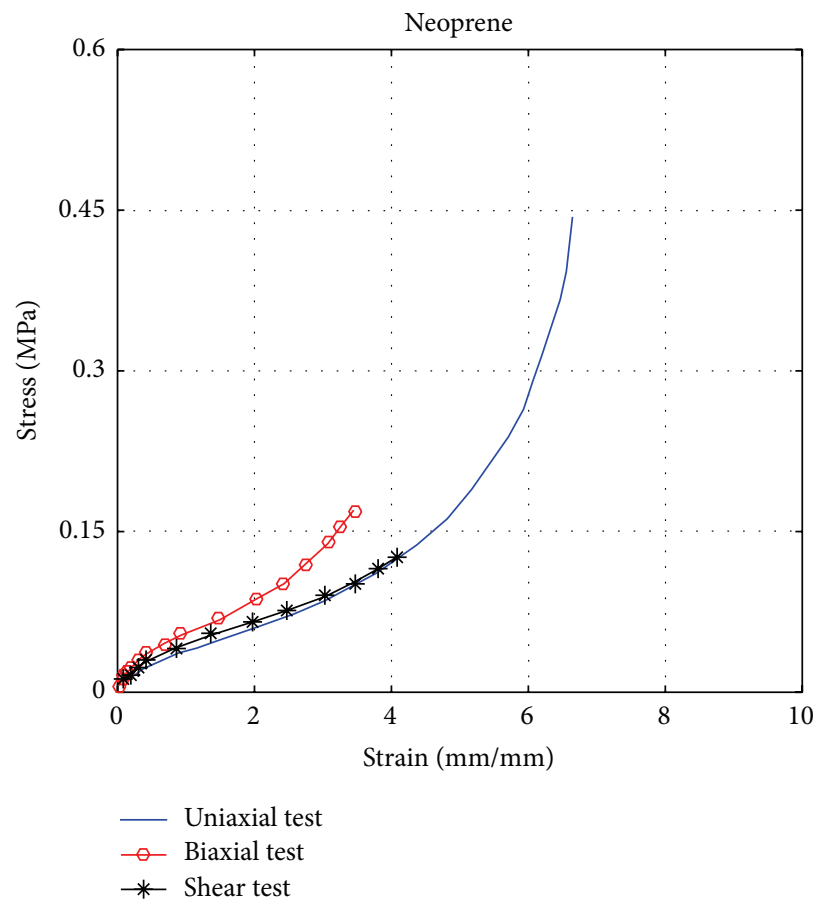

(c)

FIGURE 2: LRELS material properties.

TABLE 1: Geometry of LRELS mounts considered in the study.

\begin{tabular}{|c|c|c|c|c|c|c|}
\hline \multirow{2}{*}{ Designation } & \multicolumn{3}{|c|}{ ELS } & \multicolumn{2}{|c|}{ Leaf spring } & \multirow[b]{2}{*}{$\phi(\mathrm{mm})$} \\
\hline & Length $A(\mathrm{~mm})$ & Width $B(\mathrm{~mm})$ & Height $C(\mathrm{~mm})$ & $H(\mathrm{~mm})$ & $D(\mathrm{~mm})$ & \\
\hline LRELS 1 & 216 & 50.8 & 107 & 94.62 & 76.2 & 13 \\
\hline LRELS 2 & 216 & 76.2 & 107 & 94.62 & 76.2 & 13 \\
\hline LRELS 3 & 216 & 101.6 & 107 & 94.62 & 76.2 & 13 \\
\hline LRELS 4 & 216 & 101.6 & 107 & 94.62 & 101.6 & 13 \\
\hline
\end{tabular}




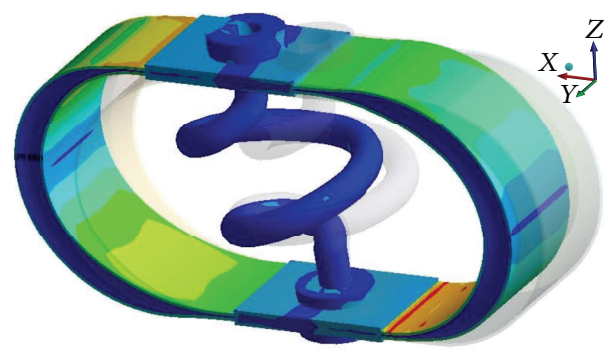

(a) In-plane

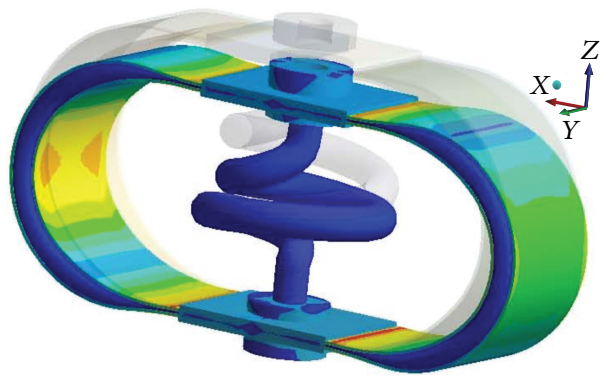

(c) Compression

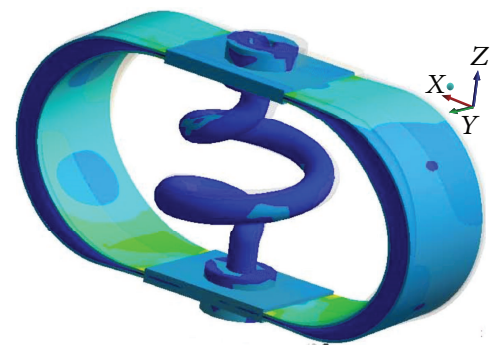

(b) Out-of-plane

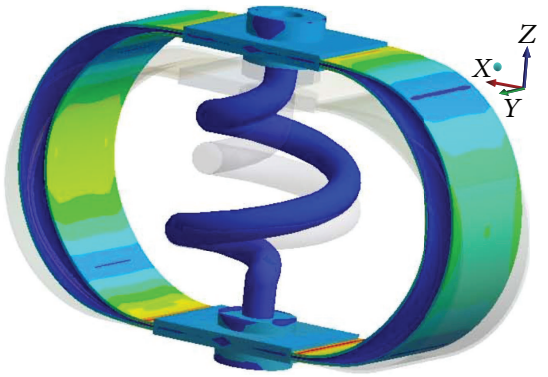

(d) Tension

FIGURE 3: Deformed shapes of LRELS 1.

spring shape with a nonsymmetrical geometry across all three planes, thus restricting any possible simplified modeling. All nodes at the bottom of the isolator (bottom face plate) were fixed while nodes at the top surface were subjected to a displacement controlled load in the direction of interest. In applying the displacement in one direction, nodes at the top of surface (top face plate) of the finite element model were restricted from moving in the other two directions to simulate the real experimental conditions [3, 10, 33-35] and also to isolate the behavior of the LRELS's behavior in the direction of interest independently of the other directions. In this way, for example, applying an in-plane horizontal displacement at the top of the isolator while restricting the movement in the vertical and out-of-plane directions results in an accurate estimation of the shear behavior. Figure 4 shows the forcedisplacement curves for LRELS 1 obtained from the FEA; it can be observed that the LRELS isolators exhibit nonlinear hysteretic behavior. The responses of the ELS and lead spring are separately provided in the same figure. It can be observed that the addition of the lead spring introduces the damping to the system and, further, enhances the energy dissipation of the ELS. The results of the FEA for all the cases are discussed in the next sections along with their mathematical models.

\section{Mathematical Modeling}

The LRELS exhibits different behaviors in different directions (Figure 4); hence, the mathematical models are developed in this section for each loading direction. These models are calibrated using FEA results. The effectiveness of the LRELS through its stiffness, damping, and energy dissipation capabilities is discussed later.
4.1. In-Plane Horizontal Direction. Figure 4(a) shows the force-displacement curves for the ELS and the lead spring separately in the in-plane direction. The total force mobilized in the LRELS isolator can be expressed as the sum of the forces from the ELS and from the lead spring; that is,

$$
F(\text { ELS })+F(\text { lead spring })=F(\text { LRELS }) .
$$

The lead spring has an elastic, almost perfectly plastic behavior and the ELS behaves elastically, indicating that the energy dissipation is the property of the lead spring only. However, the ELS behavior is the mechanism by which the LRELS is able to store elastic energy as in the lead-rubber bearing isolators [36]. The in-plane horizontal behavior of all isolators represents classical symmetrical hysteretic behavior and can be modeled using the Bouc-Wen model of hysteresis $[25,26]$. The force mobilized in the isolator is expressed as the sum of an elastic and a hysteretic part (Figure 5):

$$
F=F(\text { LRELS })=k_{p} x+Q z,
$$

where $x$ is the in-plane horizontal displacement and $z$ is a dimensionless quantity taking values in the range $[-1,1]$ and is given by the following differential equation:

$$
\dot{z}=\frac{\dot{x}}{x_{y}}\left[A-|z|^{n}(\gamma \operatorname{sign}(\dot{x} z)+\beta)\right],
$$

where $A, \gamma, \beta$, and $n$ are dimensionless quantities that control the shape of the hysteresis loop and $k_{p}, Q$, and $x_{y}$ are the postelastic stiffness, yield strength, and the yield displacement, respectively.

For the analytical modeling of the isolator in the in-plane horizontal direction, the values $A=1, \gamma=0.5, \beta=0.5$, and 


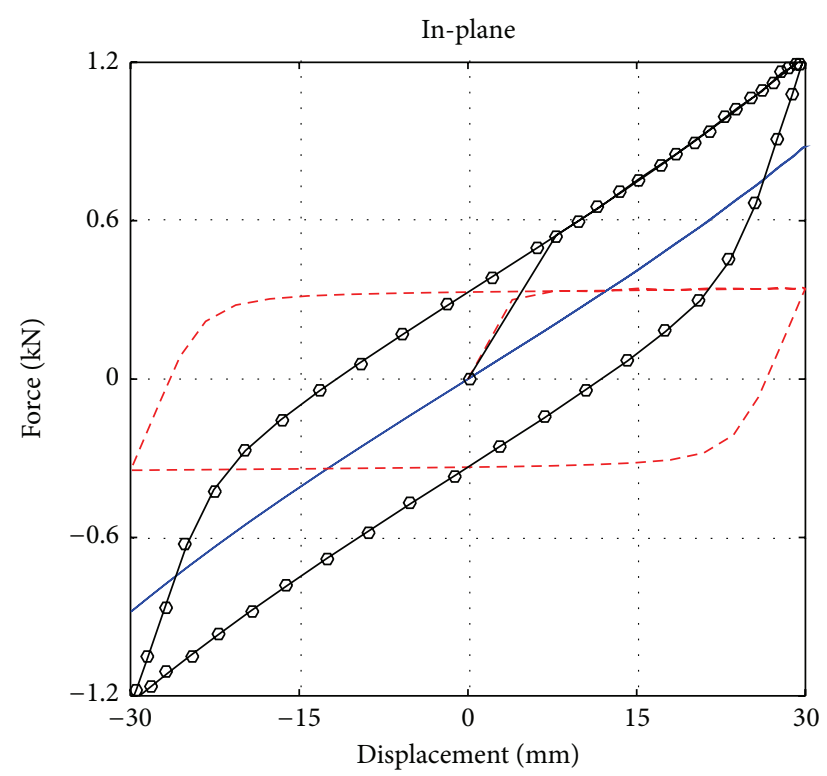

(a)

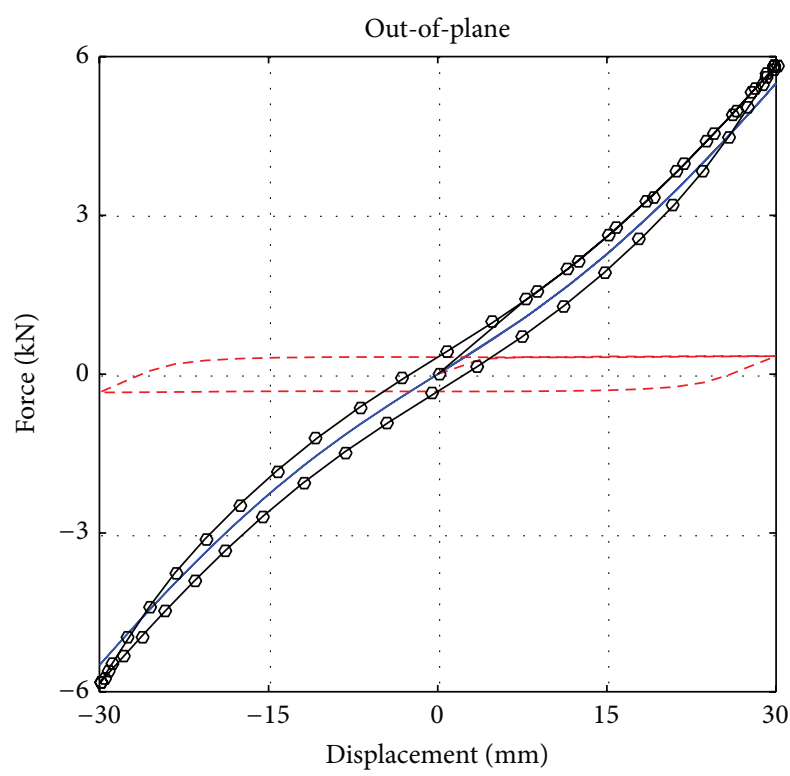

(b)

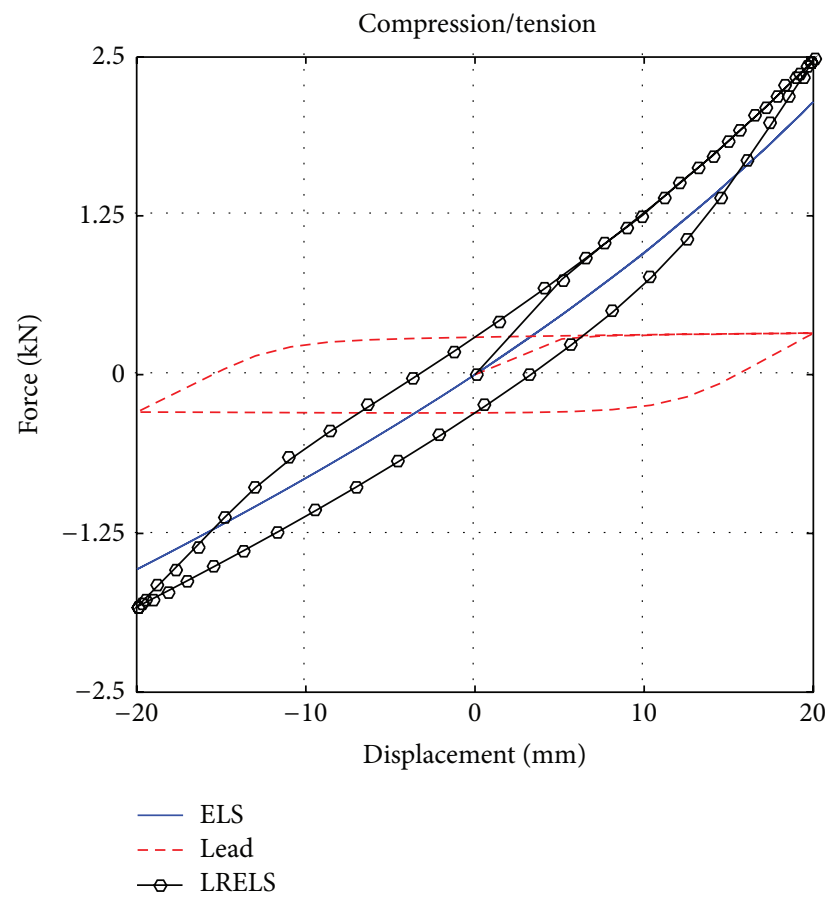

(c)

FIGURE 4: Force-displacement curves for LRELS 1: (a) in-plane (b); out-of-plane; (c) compression/tension.

$n=2$ were used. The other parameters of the hysteresis model were identified using the least squares method and are listed in Table 2. Figure 6 shows the force-displacement curves for four LRELS mounts in the in-plane horizontal direction. It can be observed that the mathematical model based on the Bouc-Wen model of hysteresis is in good agreement with the results predicted using FEA.

4.2. Out-of-Plane Horizontal Direction. Figure 4(b) shows the force-displacement curve in the out-of-plane direction for both ELS and lead spring. In this load case, the behavior is symmetric; however, the force-displacement loop looks narrower than in the case of in-plane direction, indicating a lower damping ratio, and a stiffening behavior is observed after $13 \mathrm{~mm}$ of displacement. In addition, the LRELS is stiffer in the out-of-plane direction than in the in-plane direction. Hysteresis models describing the out-of-plane behavior are achieved by considering (4), which is demonstrated in Figure 4(b); the force $F$ mobilized in the isolator in the outof-plane direction is the sum of an elastic and a hysteresis 


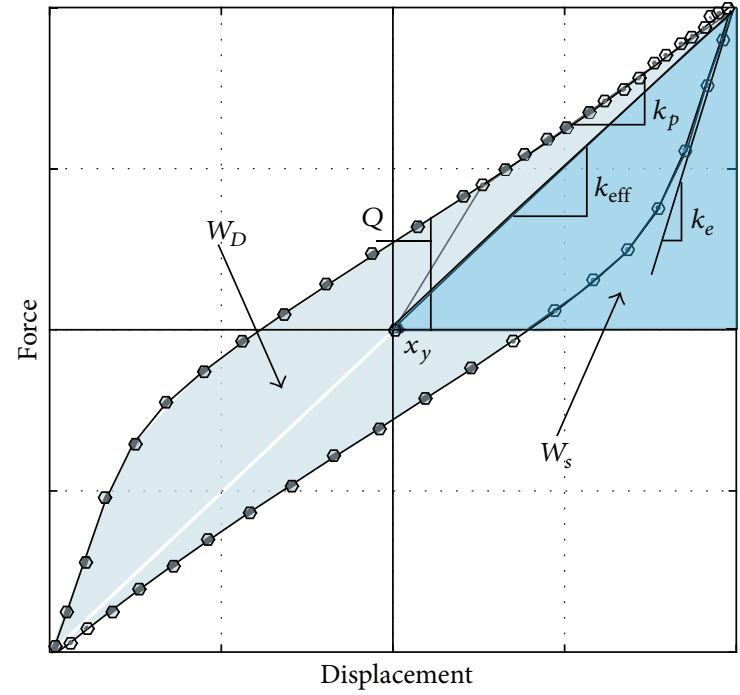

FIGURE 5: Bouc-Wen model of hysteresis.

part (Figure 7); the elastic part $(f)$ may be represented by a piecewise function while the hysteresis part is represented by the hysteresis part of the Bouc-Wen model (i.e., $(Q z))$; that is,

$$
\begin{aligned}
& F=f+Q z, \\
& f=k x+ \begin{cases}0 & x_{1} \leq x \leq x_{2} \\
k_{1}\left(x_{1}-x\right) & x<x_{1} \\
k_{2}\left(x-x_{2}\right) & x \geq x_{2} .\end{cases}
\end{aligned}
$$

The parameters used in (7a) and (7b) are defined in Figure 7, noting that $x_{1}$ and $k_{1}$ are negative quantities. The parameter $k$ represents the stiffness of the ELS prior to the stiffening behavior that occurs when the horizontal displacement exceeds $x_{1}$ (or $x_{2}$ ) after which the stiffness increases by $k_{1}$ (or by $k_{2}$ ).

Table 3 summarizes the values of the parameters used in (7a) and (7b) for all the LRELS considered in the present study. The proposed model is simple and all its parameters have physical meaning. Comparisons of analytical and finite element force-displacement curves of the isolators in the out-of-plane mode are presented in Figure 8. The proposed mathematical model predicted with good accuracy the results obtained using FEA.

4.3. Vertical Direction. Figure 4(c) shows the force-displacement curves for the ELS and the lead spring separately in the vertical direction. All isolators were analyzed numerically in the vertical (compression-tension) direction. The hysteretic behavior of the isolators in the vertical direction exhibited asymmetry due to different stiffness in tension and in compression. Figure 9 demonstrates this behavior. For example, LRELS 3 is stiffer in tension by around 45\% than in compression. In compression, the isolator exhibited bilinear behavior with stiffness softening and in tension it exhibited an increasingly stiffening behavior. This can be explained by the fact that when the vertical deformation in tension of the ELS reaches a certain threshold $\left(x_{1}\right.$ in $\left.(7 \mathrm{~b})\right)$ the steel leaves approach their limit of deformation allowed by the fixed bottom face plate,
TABle 2: Parameters of model isolators in the in-plane horizontal direction.

\begin{tabular}{lcccc}
\hline Designation & $k_{e}(\mathrm{~N} / \mathrm{mm})$ & $x_{y}(\mathrm{~mm})$ & $Q(\mathrm{~N})$ & $\alpha=k_{p} / k_{e}$ \\
\hline LRELS 1 & 132.4 & 3.30 & 340.6 & 0.22 \\
LRELS 2 & 132.4 & 3.85 & 340.6 & 0.33 \\
LRELS 3 & 132.4 & 4.60 & 340.6 & 0.44 \\
LRELS 4 & 132.4 & 3.36 & 248.2 & 0.44 \\
\hline
\end{tabular}

leading to hardening in tension, which increases with increasing load amplitudes. The same behavior has been reported by many researchers investigating the wire rope isolators ([ 3 , $8,10,37]$ among others). As a result, the energy dissipation is different in tension than it is in compression. The model of $(7 a)$ and $(7 b)$ reproduced well the numerical response as illustrated in Figure 9. The parameters of the model are tabulated in Table 4 . Note that $k_{1}$ is positive in this case.

\section{Effective Stiffness and Effective Damping}

The force-displacement behavior of the LRELS obtained from the FEA is used to determine the equivalent linear system. The performance of the LRELS can be assessed based on the effective dynamical properties (i.e., the effective stiffness and effective damping). The effective stiffness provides details on the load carrying capacity of the isolator. The effective damping is calculated based on the estimated amount of energy dissipated per cycle and the strain energy stored at maximum displacement. The equivalent linear system which is characterized by the effective stiffness and effective damping can be used to approximate the nonlinear behavior of the LRELS. In many practical designs, the vibration analysis of isolated equipment is mainly based on the equipment linear analysis, rather than a full nonlinear dynamic analysis. It should be noted that the equivalent linear system is valid only for small vibration levels since high nonlinearity is observed at large vibration amplitudes.

The lead spring in the LRELS is plugged to enhance energy dissipation of the isolator. Figure 4 shows the comparison of the force-displacement relation between ELS and LRELS. The ELS as a vibration isolation device provides the isolation through the increased flexibility of the overall system and in the special arrangement of ELS with the polymer compound between the " $U$ " shaped leaves can contribute towards the viscous damping. The isolator increased damping can provide better dissipation of the external induced disturbances. The lead spring plugged vertically in the middle of the ELS enhances the energy dissipation as demonstrated in Figure 4. The LRELS exhibits hysteresis behavior in all directions and the hysteresis curves provide a measure about the amount of energy dissipated during the loading and unloading of the isolator.

The effective stiffness $k_{\text {eff }}$ of the isolator can be calculated from the force-displacement curve in terms of the parameters $k_{p}, Q$, and the maximum displacement $x_{\max }$ (Figure 5); it is given by $[4,38,39]$

$$
k_{\mathrm{eff}}=k_{p}+\frac{Q}{x_{\max }} .
$$



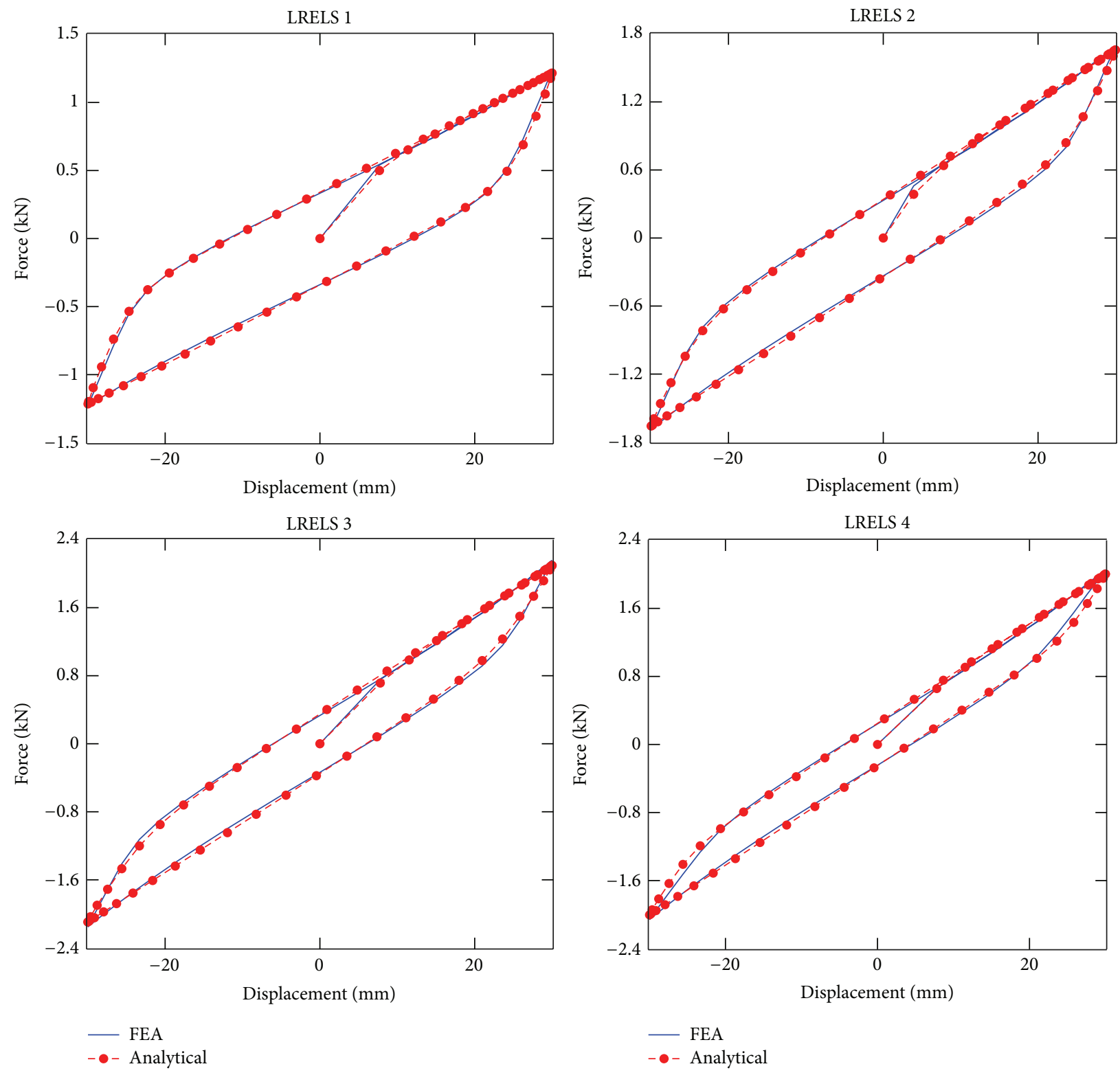

Figure 6: In-plane force-displacement curves.

TABLE 3: Parameters of model isolators in the out-of-plane horizontal direction.

\begin{tabular}{lccccccc}
\hline Designation & $Q(\mathrm{~N})$ & $x_{y}(\mathrm{~mm})$ & $k(\mathrm{~N} / \mathrm{mm})$ & $k_{1}(\mathrm{~N} / \mathrm{mm})$ & $k_{2}(\mathrm{~N} / \mathrm{mm})$ & $x_{1}(\mathrm{~mm})$ & $x_{2}(\mathrm{~mm})$ \\
\hline LRELS 1 & 330.24 & 3.32 & 145.95 & -73.93 & 75.41 & -14.94 \\
LRELS 2 & 333.92 & 2.99 & 314.98 & -179.82 & 179.40 & -13.46 \\
LRELS 3 & 343.34 & 2.75 & 594.46 & -280.83 & 281.83 & -13.22 \\
LRELS 4 & 241.13 & 2.97 & 594.29 & -282.02 & 281.14 & -13.20 \\
\hline
\end{tabular}

TABLE 4: Parameters of model isolators in the vertical direction.

\begin{tabular}{lccccccc}
\hline Designation & $Q(\mathrm{~N})$ & $x_{y}(\mathrm{~mm})$ & $k(\mathrm{~N} / \mathrm{mm})$ & $k_{1}(\mathrm{~N} / \mathrm{mm})$ & $k_{2}(\mathrm{~N} / \mathrm{mm})$ & $x_{1}(\mathrm{~mm})$ & $x_{2}(\mathrm{~mm})$ \\
\hline LRELS 1 & 298.43 & 4.44 & 95.12 & 23.29 & 27.49 & -3.49 & 12.01 \\
LRELS 2 & 300.10 & 4.62 & 151.04 & 38.08 & 45.31 & -3.68 & 11.30 \\
LRELS 3 & 304.92 & 4.78 & 212.21 & 55.75 & 66.37 & -3.61 \\
LRELS 4 & 191.56 & 8.07 & 212.54 & 54.13 & 64.32 & -3.57 & 11.24 \\
\hline
\end{tabular}




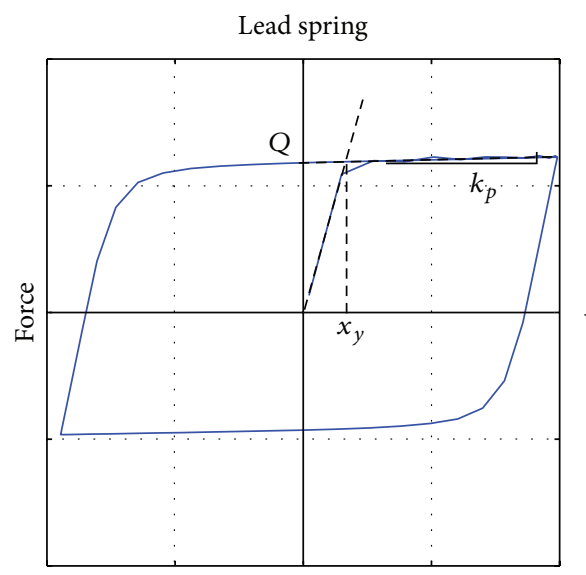

Displacement

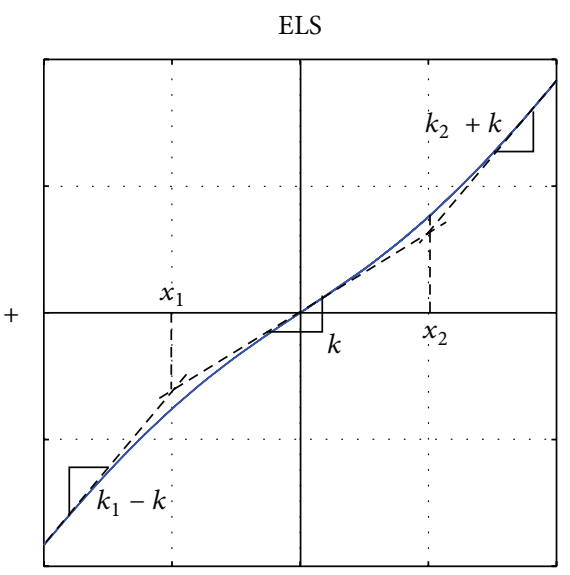

Displacement

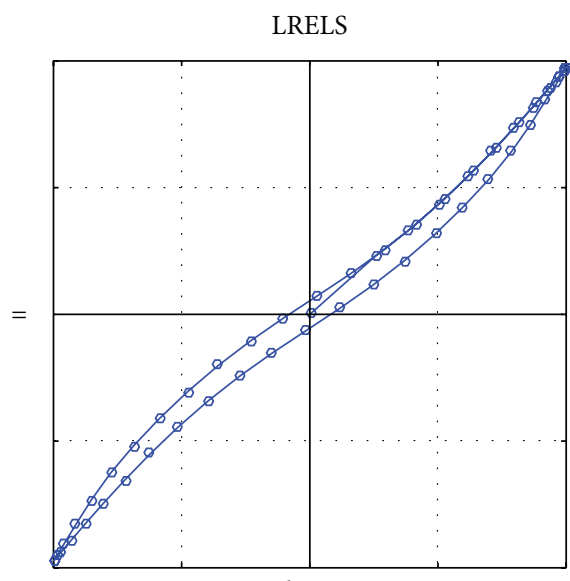

Displacement

FIGURE 7: Out-of-plane behavior: force (LRELS) = force $(E L S)+$ force (lead spring).

TABLE 5: Effective stiffness, damping, and energy dissipation in the in-plane horizontal direction.

\begin{tabular}{lcccc}
\hline Designation & $k_{\text {eff }}(\mathrm{N} / \mathrm{mm})$ & $W_{D}(\mathrm{~N} \cdot \mathrm{mm})$ & $W_{S}(\mathrm{~N} \cdot \mathrm{mm})$ & $\beta_{\text {eff }}(\%)$ \\
\hline LRELS 1 & 40.54 & 36376.08 & 18243.55 & 15.87 \\
LRELS 2 & 55.29 & 35626.76 & 24878.61 & 11.40 \\
LRELS 3 & 69.71 & 34604.96 & 31369.43 & 8.78 \\
LRELS 4 & 66.81 & 26445.00 & 30065.50 & 7.00 \\
\hline
\end{tabular}

The effective damping $\beta_{\text {eff }}$ for $x_{\max } \geq x_{y}$ is defined to be the area of the hysteresis loop, $W_{D}$, divided by $4 \pi W_{S}[4,38,39]$ :

$$
\beta_{\mathrm{eff}}=\frac{W_{D}}{4 \pi W_{S}}
$$

The area of the hysteresis loop $W_{D}$ is given by $[4,38,39]$ (see Figure 5)

$$
W_{D}=4 Q\left(x_{\max }-x_{y}\right)
$$

and $Q$ represents the energy dissipated per cycle; it is due mainly to the plastic deformation of the lead spring. The strain energy stored at maximum displacement, $W_{S}$, is given by $[4,38,39]$ (see Figure 5 )

$$
W_{S}=\frac{1}{2} k_{\mathrm{eff}} x_{\max }^{2}
$$

The effective stiffness, the effective damping, and the energy dissipation calculated for all isolators and in all three directions are presented in Tables 5-7. It is clear that increasing the isolator width increases the stiffness. Considering LRELS 1, it can be observed that the effective stiffness is approximately three times greater in the out-of-plane horizontal direction than in the in-plane direction. However, the effective damping is lower for the out-of-plane direction than in the in-plane and vertical directions, but the energy dissipated per cycle is almost the same in both horizontal directions.
TABLE 6: Effective stiffness, damping, and energy dissipation in the out-of-plane horizontal direction.

\begin{tabular}{lcccc}
\hline Designation & $k_{\text {eff }}(\mathrm{N} / \mathrm{mm})$ & $W_{D}(\mathrm{~N} \cdot \mathrm{mm})$ & $W_{S}(\mathrm{~N} \cdot \mathrm{mm})$ & $\beta_{\text {eff }}(\%)$ \\
\hline LRELS 1 & 193.71 & 29731.25 & 85509.56 & 2.77 \\
LRELS 2 & 427.69 & 34591.53 & 192589.18 & 1.43 \\
LRELS 3 & 766.10 & 5679.78 & 345253.00 & 0.13 \\
LRELS 4 & 762.20 & 6523.74 & 343470.26 & 0.15 \\
\hline
\end{tabular}

TABLE 7: Effective stiffness, damping, and energy dissipation in the vertical direction.

\begin{tabular}{lcccc}
\hline Designation & $k_{\text {eff }}(\mathrm{N} / \mathrm{mm})$ & $W_{D}(\mathrm{~N} \cdot \mathrm{mm})$ & $W_{S}(\mathrm{~N} \cdot \mathrm{mm})$ & $\beta_{\text {eff }}(\%)$ \\
\hline LRELS 1 & 121.59 & 18598.47 & 24356.47 & 6.08 \\
LRELS 2 & 186.52 & 17860.12 & 37315.60 & 3.81 \\
LRELS 3 & 257.58 & 16895.21 & 51526.15 & 2.61 \\
LRELS 4 & 251.95 & 6400.71 & 50400.04 & 1.01 \\
\hline
\end{tabular}

The energy dissipated per cycle depends on the lead spring behavior, and since the force-displacement behavior of the latter is almost the same in both horizontal directions, this energy would be approximately the same. The increased stiffness of the LRELS in all directions enables its use in the isolation of heavier equipment. The damping contribution of the lead spring can be advantageous in the region of resonance, by reducing the transmissibility. The higher effective damping in the in-plane horizontal direction indicates that the recommended orientation of the LRELS when used to isolate equipment is the in-plane direction.

\section{Conclusions}

The elliptical leaf spring (ELS) lacks damping and energy dissipation capacity. In this paper, we investigated a method to enhance the ELS by plugging a lead spring between the upper and lower face plates of the " $U$ " shaped stainless 

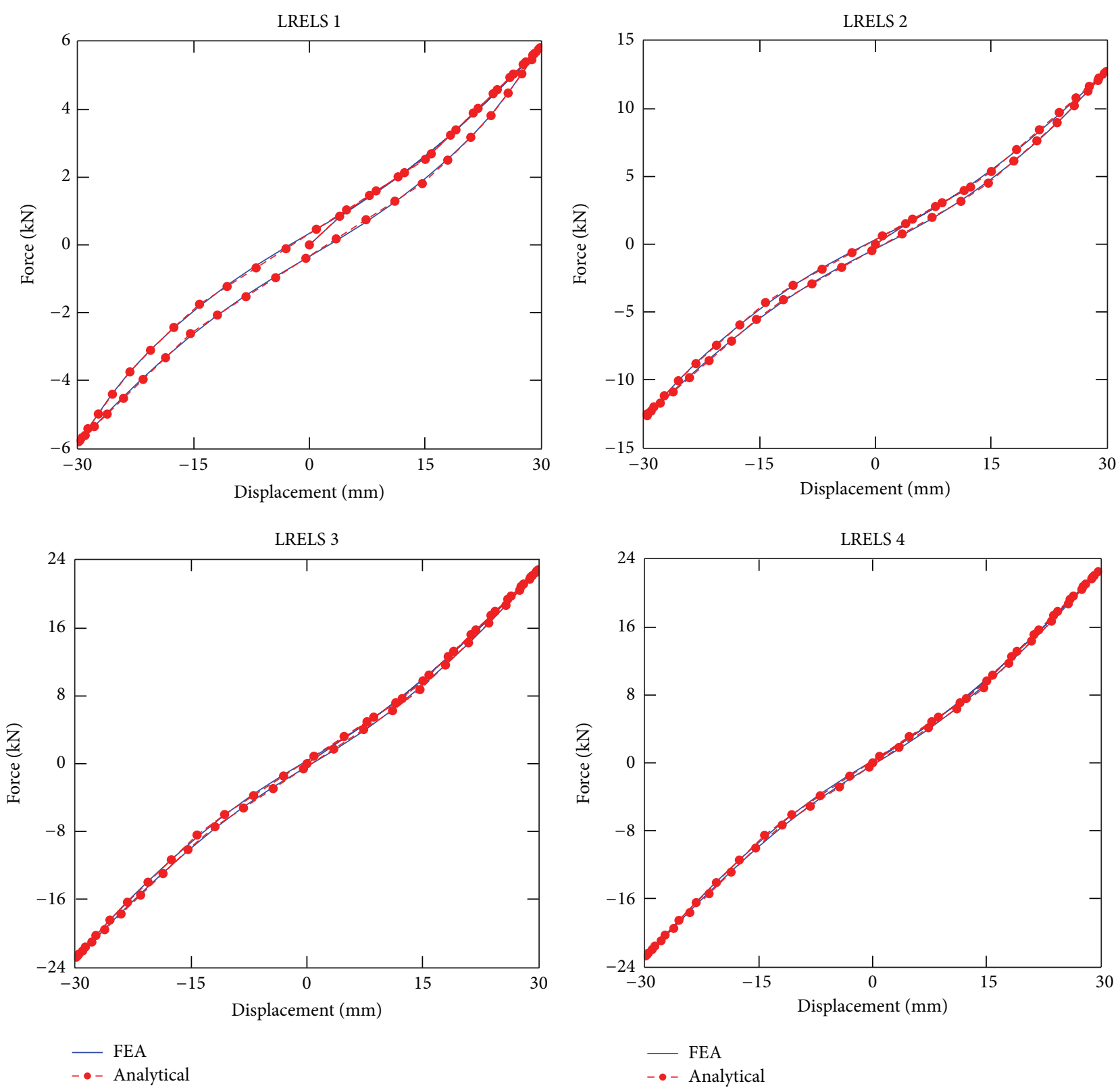

FIGURE 8: Out-of-plane force-displacement curves.

steel leaves. Full three-dimensional finite element analysis demonstrated that the plugged lead spring has provided an improvement in the effective stiffness, effective damping, and energy dissipation, especially in the in-plane horizontal direction. In addition, we developed mathematical models that describe the nonlinear cyclic behavior of the new improved device. These models were validated and calibrated using a series of finite element analyses.

Nevertheless, the presented results should provide a basis for understanding the behavior of the ELS and the LRELS in the three planes. In the future, experimental studies will be carried out for an enhanced calibration of the parameters of the mathematical models and to extend the study to include the dynamic performance of equipment mounted on several LRELS isolators.

\section{Conflict of Interests}

The authors declare that there is no conflict of interests regarding the publication of this paper.

\section{Acknowledgments}

This paper is based upon the work supported by the Sustainable Construction Materials and Structural Systems Research 

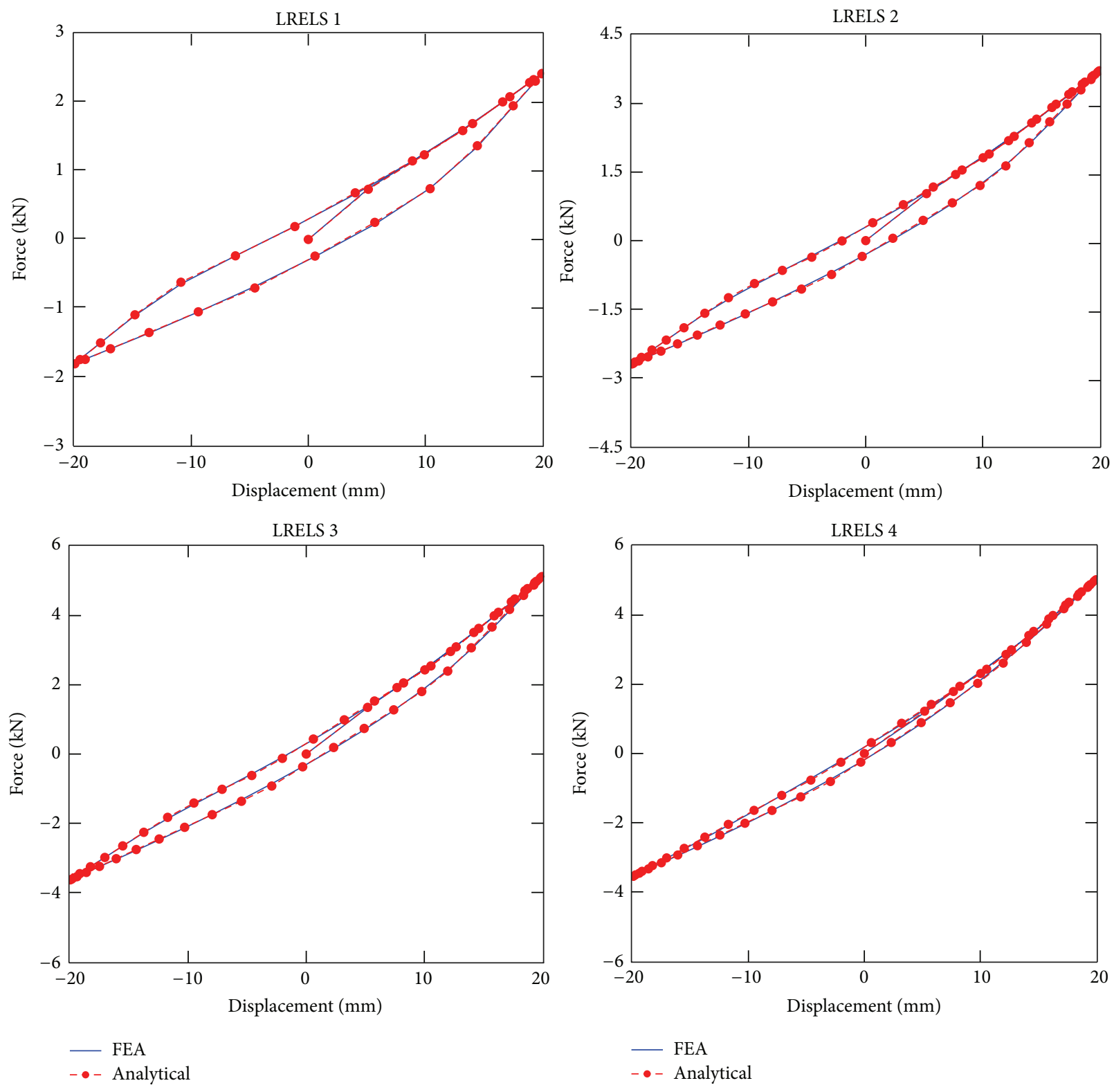

Figure 9: Vertical force-displacement curves.

Group, University of Sharjah, Sharjah, UAE, and the Ministry of Higher Education (MOHE), Malaysia, under the ERGS Grant Scheme.

\section{References}

[1] G. W. Housner, L. A. Bergman, T. K. Caughey et al., "Structural control: past, present, and future," Journal of Engineering Mechanics, vol. 123, no. 9, pp. 897-971, 1997.

[2] S. Naranjo, L. Hong-Nan, and L. Gang, Simple Method for Pushover Curves of Asymmetric Structure with DisplacementDependent Passive Energy Dissipation Devices, Summer Research Program in Marine Science and Engineering, Clarkson University, Potsdam, NY, USA; Dalian University of Technology, Dalian, China, 2006.
[3] G. F. Demetriades, M. C. Constantinou, and A. M. Reinhorn, "Study of wire rope systems for seismic protection of equipment in buildings," Engineering Structures, vol. 15, no. 5, pp. 321-334, 1993.

[4] F. Naeim and J. M. Kelly, Design of Seismic Isolated Structures: From Theory to Practice, John Wiley \& Sons, New York, NY, USA, 1999.

[5] F. Naeim, The Seismic Design Handbook, Springer, Berlin, Germany, 1989.

[6] K. Kosar, T. T. Soong, K. Shen, J. HoLung, and Y. Lin, Seismic Testing of Installation Methods for Computers and Data Processing Equipment, National Center for Earthquake Engineering Research, 1993.

[7] N. Makris and M. C. Constantinou, "Spring-viscous damper systems for combined seismic and vibration isolation," 
Earthquake Engineering \& Structural Dynamics, vol. 21, no. 8, pp. 649-664, 1992.

[8] P. S. Balaji, L. Moussa, M. E. Rahman, and L. T. Vuia, "Experimental investigation on the hysteresis behavior of the wire rope isolators," Journal of Mechanical Science and Technology, vol. 29, no. 4, pp. 1527-1536, 2015.

[9] P. S. Balaji, M. E. Rahman, L. Moussa, and H. H. Lau, "Wire rope isolators for vibration isolation of equipment and structures-a review," IOP Conference Series: Materials Science and Engineering, vol. 78, Article ID 012001, 2015.

[10] H. Wang, X. Gong, F. Pan, and X. Dang, "Experimental investigations on the dynamic behaviour of o-type wire-cble vibration isolators," Shock and Vibration, vol. 2015, Article ID 869325, 12 pages, 2015.

[11] A. Nacamuli, "Seismic protection of data centers using ball-Ncone base isolation," in Proceedings of the Structures Congress, pp. 1373-1384, American Society of Civil Engineers, 2012.

[12] I.-K. Chang, S.-C. Liu, and H. C. Shah, "Seismic support of electronic and computer equipment on raised floors," Soil Dynamics and Earthquake Engineering, vol. 5, no. 3, pp. 159-169, 1986.

[13] S. Liu and G. P. Warn, "Seismic performance and sensitivity of floor isolation systems in steel plate shear wall structures," Engineering Structures, vol. 42, pp. 115-126, 2012.

[14] S. Cui, M. Bruneau, and A. Kasalanati, "Behavior of bidirectional spring unit in isolated floor systems," Journal of Structural Engineering, vol. 136, no. 8, pp. 944-952, 2010.

[15] M. Hamidi and M. H. El Naggar, "On the performance of SCF in seismic isolation of the interior equipment of buildings," Earthquake Engineering \& Structural Dynamics, vol. 36, no. 11, pp. 1581-1604, 2007.

[16] V. Lambrou, C. Constantinou, and National Center for Earthquake Engineering Research, Study of Seismic Isolation Systems for Computer Floors, National Center for Earthquake Engineering Research, 1994.

[17] F. F. Tajirian, J. M. Kelly, and I. D. Aiken, "Seismic isolation for advanced nuclear power stations," Earthquake Spectra, vol. 6, no. 2, pp. 371-401, 1990.

[18] E. Mahdi, O. M. S. Alkoles, A. M. S. Hamouda, B. B. Sahari, R. Yonus, and G. Goudah, "Light composite elliptic springs for vehicle suspension," Composite Structures, vol. 75, no. 1-4, pp. 24-28, 2006.

[19] E. Mahdi and A. M. S. Hamouda, "An experimental investigation into mechanical behavior of hybrid and nonhybrid composite semi-elliptical springs," Materials \& Design, vol. 52, pp. 504-513, 2013.

[20] H. A. Al-Qureshi, "Automobile leaf springs from composite materials," Journal of Materials Processing Technology, vol. 118, no. 1-3, pp. 58-61, 2001.

[21] AAC, Aeroflex Isolators for Shock and Vibration, 2014, http:// www.vibrationmounts.com/.

[22] Y. W. Chan, S. O. Oyadiji, G. R. Tomlinson, and J. R. Wright, "Predicting the vibration characteristics of elements incorporating incompressible and compressible viscoelastic materials," in Smart Structures and Materials 1995: Passive Damping, vol. 2445 of Proceedings of SPIE, pp. 293-303, San Diego, Calif, USA, May 1995.

[23] W. H. Robinson, "Lead-rubber hysteretic bearings suitable for protecting structures during earthquakes," Seismic Isolation and Protective Systems, vol. 2, no. 1, pp. 5-19, 2011.

[24] M. E. Reys, "An introduction to seismic isolation by R.I. Skinner, W.H. Robinson and G.H. McVerry," Strain, vol. 29, no. 3, pp. 99100, 1993.
[25] Y.-K. Wen, "Method for random vibration of hysteretic systems," Journal of the Engineering Mechanics Division, vol. 102, no. 2, pp. 249-263, 1976.

[26] M. Ismail, F. Ikhouane, and J. Rodellar, "The hysteresis BoucWen model, a survey," Archives of Computational Methods in Engineering, vol. 16, no. 2, pp. 161-188, 2009.

[27] ANSYS, ANSYS Release 14. Documentation, 2011.

[28] M. Ismail, J. Rodellar, and F. Ikhouane, "An innovative isolation bearing for motion-sensitive equipment," Journal of Sound and Vibration, vol. 326, no. 3-5, pp. 503-521, 2009.

[29] P. S. Balaji and V. Yadava, "Three dimensional thermal finite element simulation of electro-discharge diamond surface grinding," Simulation Modelling Practice and Theory, vol. 35, pp. 97117, 2013.

[30] S. J. Owen, S. A. Canann, and S. Saigal, "Pyramid elements for maintaining tetrahedra to hexahedra conformability," ASME Applied Mechanics Division-Publications-AMD, vol. 220, pp. 123-130, 1997.

[31] V. Dias, C. Odenbreit, O. Hechler, F. Scholzen, and T. Ben Zineb, "Development of a constitutive hyperelastic material law for numerical simulations of adhesive steel-glass connections using structural silicone," International Journal of Adhesion and Adhesives, vol. 48, pp. 194-209, 2014.

[32] R. S. Rivlin and D. W. Saunders, "Large elastic deformations of isotropic materials. VII. Experiments on the deformation of rubber," Philosophical Transactions of the Royal Society of London A: Mathematical, Physical and Engineering Sciences, vol. 243, no. 865, pp. 251-288, 1951.

[33] J. M. Kelly and S. Takhirov, "Analytical and numerical study on buckling of elastomeric bearings with various shape factors," UCB/EERC 2004/03, Earthquake Engineering Research Center, University of California, Berkeley, Calif, USA, 2004.

[34] J. M. Kelly and S. M. Takhirov, "Tension buckling in multilayer elastomeric isolation bearings," Journal of Mechanics of Materials and Structures, vol. 2, no. 8, pp. 1591-1605, 2007.

[35] G. F. Demetriades, M. C. Constantinou, and A. M. Reinhorn, "Study of wire rope systems for seismic protection of equipment in buildings," Report No. NCEER-92-0012, National Center for Earthquake Engineering Research, 1992.

[36] W. Robinson, "Passive control of structures, the New Zealand experience," ISET Journal of Earthquake Technology, vol. 35, pp. 63-75, 1998.

[37] P. S. Balaji, M. E. Rahman, L. Moussa, and H. H. Lau, "Wire rope isolators for vibration isolation of equipment and structures-a review," IOP Conference Series: Materials Science and Engineering, vol. 78, Article ID 012001, 2015.

[38] A. K. Chopra, Dynamics of Structures: Theory and Applications to Earthquake Engineering, Prentice Hall, New York, NY, USA, 3rd edition, 2007.

[39] A. K. Chopra and R. K. Goel, "Capacity-demand-diagram methods for estimating seismic deformation of inelastic structures: SDF systems," PEER 1999/02, Pacific Earthquake Engineering Research Center, University of California, Berkeley, Calif, USA, 1999. 

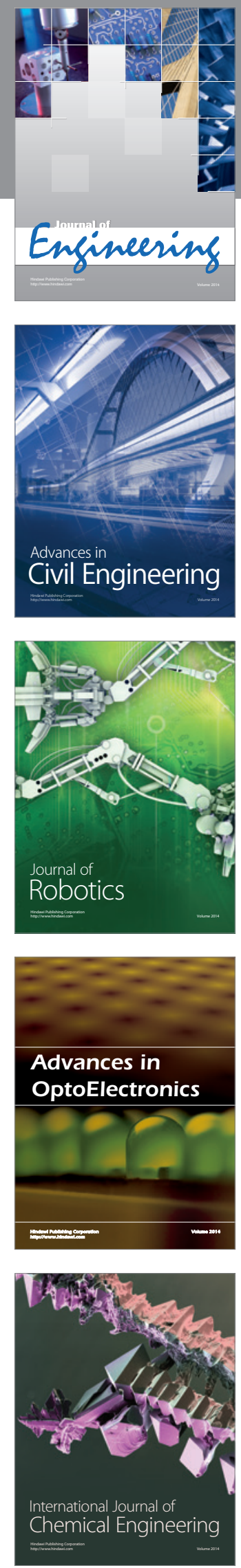

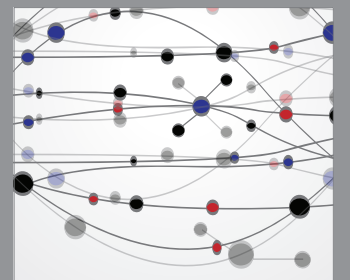

The Scientific World Journal
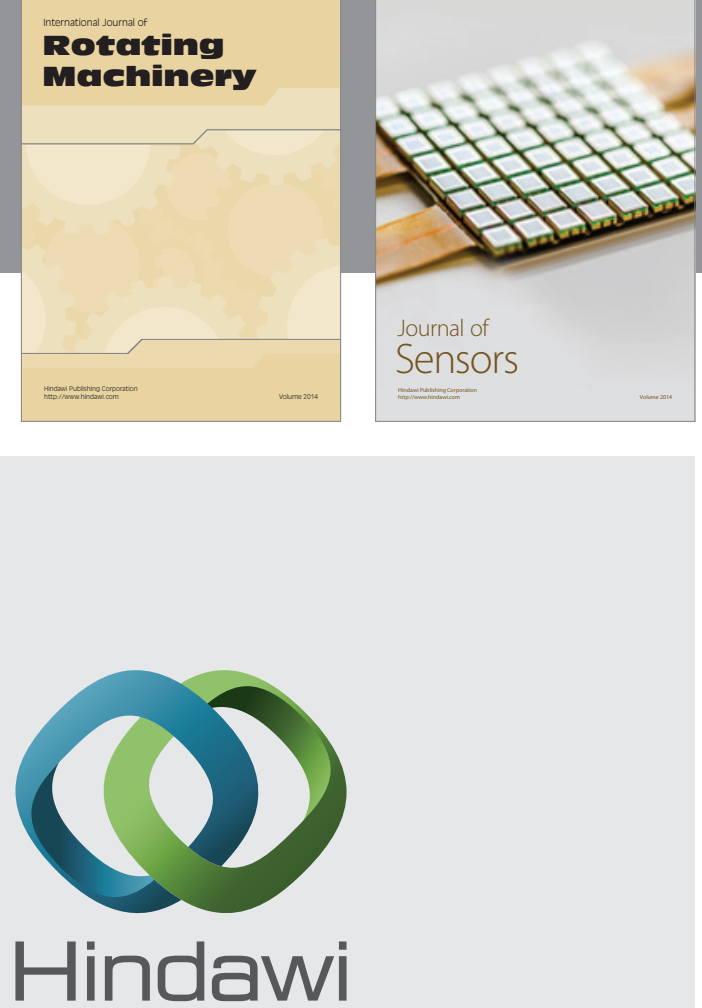

Submit your manuscripts at http://www.hindawi.com
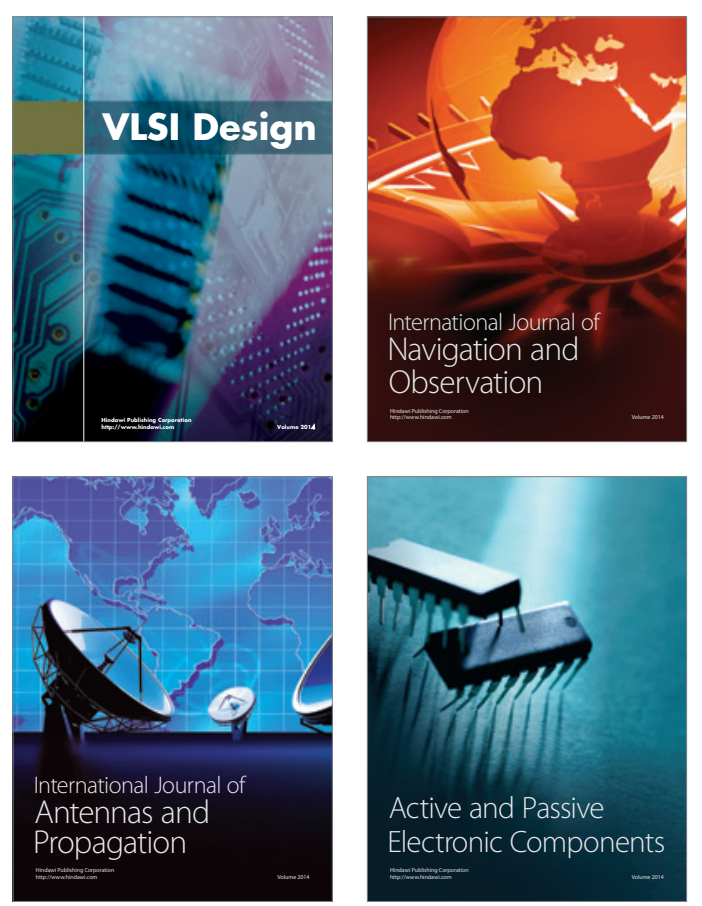
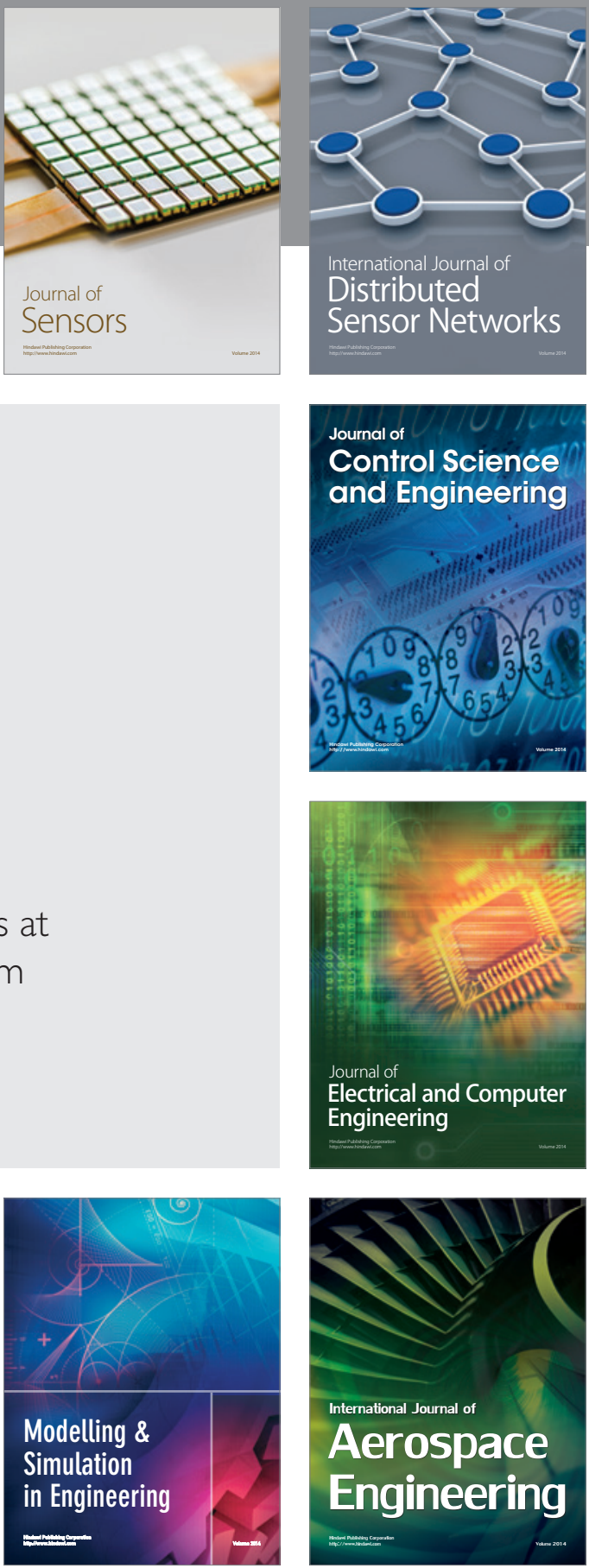

Journal of

Control Science

and Engineering
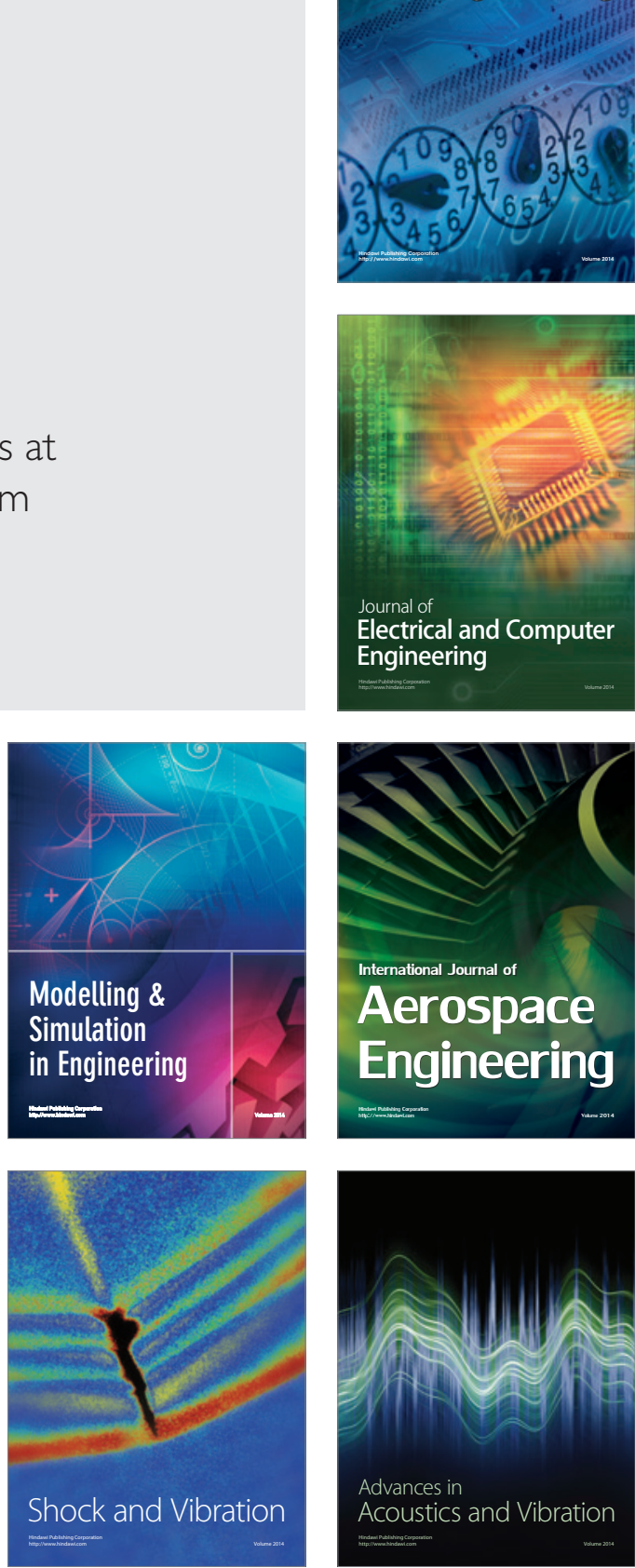